\title{
Internal accuracy of digitally fabricated cross-arch yttria-stabilized tetragonal zirconia polycrystalline prosthesis
}

This article was published in the following Dove Press journal:

Clinical, Cosmetic and Investigational Dentistry

\author{
Niwut Juntavee' \\ Issarawas Sirisathit ${ }^{2}$ \\ 'Department of Prosthodontics, \\ Faculty of Dentistry, Khon Kaen \\ University, Khon Kaen, Thailand; \\ ${ }^{2}$ Division of Biomaterials and \\ Prosthodontics Research, Faculty \\ of Dentistry, Khon Kaen University, \\ Khon Kaen, Thailand
}

Objective: This investigation determined the internal precision of one-piece cross-arch yttria partially stabilized tetragonal zirconia polycrystalline (Y-TZP) ceramic fabricated from two digital systems (Trios-3 and CS-3500) compared to traditional metal alloy casting.

Materials and methods: A metal model consisting of four abutments (two canine and two molar) was used for one-piece cross-arch reconstruction. The metal abutments were computerized, prepared in a cylinder form possessing $5^{\circ}$ taper and chamfer margin. Two digital approaches of computer-aided design and computer-aided manufacturing were used to fabricate one-piece cross-arch Y-TZP prostheses. The traditional lost wax technique was used to fabricate conventional cast prostheses with nonnoble metal alloys. Ten prostheses were constructed from each system. The preciseness of the prosthesis was evaluated at 22 positions for each abutment using a digital stereomicroscope. Analysis of variance (ANOVA) and Tukey's method were determined for all pairwise differences at the $95 \% \mathrm{CI}$.

Results: The means and SDs of internal accuracy of prostheses constructed from the traditional cast technique, Trios-3, and CS-3500 were $75.15 \pm 13.46 \mu \mathrm{m}, 78.55 \pm 14.30 \mu \mathrm{m}$, and $82.43 \pm 16.32 \mu \mathrm{m}$, respectively. ANOVA revealed statistical significance for the internal accuracy of prostheses between the different techniques at different positions of each abutment. Preciseness of the Y-TZP prosthesis constructed from Trios-3 illustrated significantly better internal fit than that constructed from CS-3500 $(p<0.05)$. Tukey multiple comparisons revealed that the Y-TZP prosthesis constructed from both digital systems displayed significantly less internal fit than the traditionally fabricated prosthesis $(p<0.05)$.

Conclusion: The one-piece cross-arch Y-TZP prosthesis constructed from Trios-3 demonstrated superior internal accuracy than that from CS-3500, but both slightly lower in accuracy than the traditional cast metal prosthesis. Nevertheless, the internal discrepancies of the Y-TZP prosthesis fabricated by both digital techniques were not beyond the range of clinical prestige and were convincingly precise to be recommended for one-piece cross-arch extensive reconstruction.

Keywords: digital dentistry, extensive reconstruction, internal accuracy, internal fit, zirconia

\section{Introduction}

The accomplishment of fixed dental prostheses depends upon the capability of the prosthesis to withstand the stress of the physiologic masticatory function and possess similar aesthetics to the natural tooth with accurate fit of the prosthesis to the abutment. ${ }^{1}$ Longrange successful fixed dental prostheses are predominately governed by the preciseness of the restorative material used for construction of the fixed prosthesis. ${ }^{2,3}$ Imprecise fixed dental prostheses usually induce microbacteria accumulation on the plaque, which instigates periodontal disease, and causes secondary caries leading to failure of the
Correspondence: Niwut Juntavee Department of Prosthodontics, Faculty of Dentistry, Khon Kaen University, 123 Mitraphap Road, Khon Kaen 40002, Thailand

Tel +66897 II 2980

Email niwutpapa@hotmail.com 
dental prosthesis. ${ }^{2,4}$ Most patients often ask for tooth-color restoration, which gives rise to dental ceramic being the first priority in restorative material selection for advanced fixed prosthodontic reconstruction. Many modern dental ceramic materials have been formulated with enhanced strengths for resisting physiologic force generated from mastication and serving as full-arch fixed dental prostheses. ${ }^{5,6}$ The yttria partially stabilized tetragonal zirconia polycrystal (Y-TZP) has currently been proposed among modern restorative ceramics since it possesses aesthetic properties, biocompatibility, minimal bacterial plaque adhesion, and low thermal conduction as well as remarkable strength and admirable fracture resistance. ${ }^{1,5,7}$ A typical feature of yttria-stabilized zirconia, in consideration of the toughened property related to phase transformation, is that has been described to be capable of effectively impeding crack propagation. ${ }^{8}$

The Y-TZP dental prostheses can be constructed from the advanced digital technology of computer-aided design and computer-aided manufacturing (CAD-CAM). ${ }^{1,6}$ The Y-TZP milling procedure is accomplished by use of either a partially sintered or a completely sintered Y-TZP block. The milling process using a completely sintered blank of Y-TZP to generate the definite shape and dimension of the dental prosthesis produces a precise fit of the dental prosthesis, approximately 60.4-74.0 $\mu \mathrm{m}$ of internal space, since the procedure does not demand an additional firing procedure, hence eradicating the dimensional shrink down of zirconia from the sintering process. ${ }^{9,10}$ However, it easily causes damage to the grinding bur as well as consumes a longer processing time. ${ }^{3}$ Another technique of zirconia milling based on using a partially sintered Y-TZP blank is simply a machining process but this procedure requires additionally firing to derive a completely matured zirconia prosthesis. The prosthesis must be sketched out in a size increased by approximately $15 \%-30 \%$ before executing the milling procedure to counteract dimensional shrinkage upon firing of the Y-TZP. ${ }^{11,12}$ The inaccuracy of the zirconia restorations increases as the restorations involve extreme extension. ${ }^{11}$ The other possible sources of imprecise fit of the zirconia restoration may also be related to the technical scanning procedures, accuracy of designing software, and capability of the milling machine., $9,13,14$

A number of CAD-CAM systems are available with varied capabilities that may influence the accuracy of the prosthesis. ${ }^{2,15,16}$ Nevertheless, potentially suitable zirconia materials for fabrication of multiunit fixed dental prostheses were reported mostly based upon the load bearing ability of the prostheses. ${ }^{11,17,18}$ Preciseness of a prosthesis has been described to be a crucial part in the fabrication process of the prosthesis which gives rise to the survival of the prosthesis. A dental prosthesis with precise fit was described to reduce the possibility of problems related to prepared tooth abutment and enhances successful treatment. ${ }^{4,17}$ A study related to imprecise fit of a CAD-CAM generated Y-TZP fixed dental prosthesis reported $21.7 \%$ of demineralization at the cavosurface margin of tooth abutment after 5 years. ${ }^{17}$ It is generally accepted that accuracy is responsible for the success and reliability of prostheses under masticatory function. ${ }^{15,17,19-22}$ It was reported that an unsuitable cement film thickness induces tensile stresses at the intaglio surface of the prosthesis as the deformation of the luting cement upon fatigue load. ${ }^{23,24}$ This phenomenon can initiate a crack in the zirconia ceramic. ${ }^{17,19,24}$

A number of digital approaches for fabricating prostheses being proposed for dentistry should illustrate that the capabilities in construction of the prostheses are considerably commensurable with pertaining to the preciseness of the traditional cast metal fabrication procedure. A precise fit of the prosthesis to the prepared tooth abutment is essential for ensuring preciseness in addition to practicability of the cementing process. During cementation, in order to derive for appropriately settling the prosthesis in place, an appropriated space of approximately $25-50 \mu \mathrm{m}$ for luting cement is needed. ${ }^{16}$ It is essential to evaluate the preciseness of onepiece cross-arch zirconia fixed prostheses constructed from different CAD-CAM systems. Therefore, it is necessary for all prostheses to be determined for preciseness to ensure quality. Up to this study, there was rare evidence of the accuracy of Y-TZP prostheses constructed from partially sintered zirconia ceramic for one-piece cross-arch prostheses. Therefore, this study aims to determine the internal fit of Y-TZP cross-arch prostheses fabricated from two digital systems, Trios- 3 and CS-3500, compared to the traditional one-piece cross-arch metal casting technique. The null hypothesis was purposed with comparable preciseness of a one-piece cross-arch Y-TZP prosthesis constructed from either the Trios-3 or CS-3500 system to the conventional one-piece cross-arch metal cast prosthesis.

\section{Materials and methods Customized metal model fabrication}

A customized metal model of a full-arch partial edentulous area, consisting of two canine abutments and two molar abutments, was constructed from stainless steel (Figure 1A) by computerized numerical control machine (CNC; Twincity EDM, Fridley, MN, USA). ${ }^{25}$ Each metal abutment was milled in a cylindrical shape, having a chamfer finishing line and 8 
A

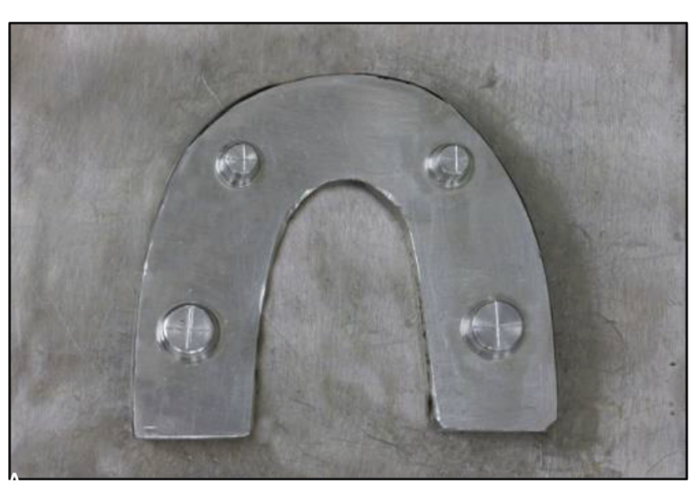

B

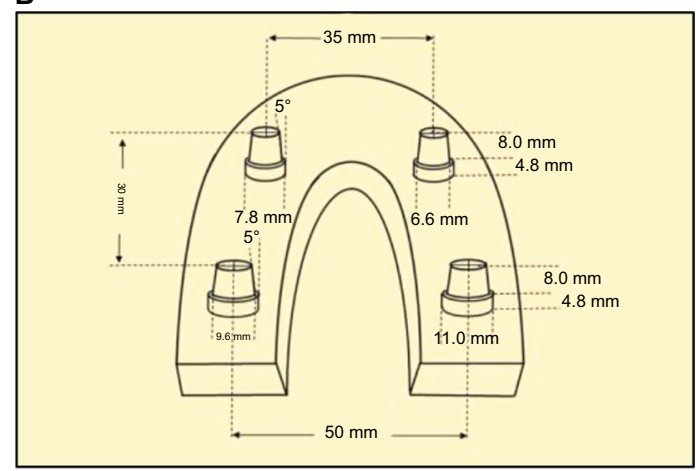

Figure I Metal model comprising two canine and two molar abutments assembled on a metal sheet (A) in definite dimensions (B).

mm height of the axial surface with a $5^{\circ}$ taper to the long axis, rendering $10^{\circ}$ of the total convergence angle. The canine was milled for a $1.2 \mathrm{~mm}$ width of chamfer margin and featured a circular shape with $6.6 \mathrm{~mm}$ and $7.8 \mathrm{~mm}$ for inner and outer diameters, respectively. The molar was milled for a $1.4 \mathrm{~mm}$ width of chamfer margin and possessed a circular shape with $9.6 \mathrm{~mm}$ and $11.0 \mathrm{~mm}$ for internal and external diameters, respectively. The metal abutments were rigidly fixed to the metal sheet to simulate a partial edentulous arch form having a span of $35 \mathrm{~mm}$ between the center of two canines, 50 $\mathrm{mm}$ between the center of two molars, and $30 \mathrm{~mm}$ from the center of the canine to the molar on an identical quadrant (Figure 1B). A customized metal arch form was used to fabricate a one-piece cross-arch fixed prosthesis, consisting of four retainers with four anterior pontics between canine retainers and two premolar pontics between canine and molar retainers on both sides.

\section{Construction of zirconia prosthesis}

The one-piece cross-arch Y-TZP prostheses were digitally constructed from either the Trios-3 (3Shape A/S, Copenhagen, Denmark) or the CS-3500 (Carestream Health, Rochester, NY, USA) digital system. The impressions of a metal model were digitally generated 10 times for each technique using the intraoral digital scanning device. The scanned files were converted to standardized transformation language files for replication polymer casts (Fotodent ${ }^{\circledR}$; Dreve Dentamid GmbH, Unna, Germany) from a computerized control appliance (ProMaker ${ }^{\circledR}$ D35; Prodways, Les Mureaux, France). Ten replicated polymer casts were generated for each digital technique. One-piece cross-arch zirconia prostheses were contrived from either Ceramill ${ }^{\circledR}$ Mind CAD software (Amann Girrbach AG, Koblach, Austria) or Trios-3 CAD software (3Shape A/S). The digitally formulated files of prostheses from Trios-3 were transmitted for milling prostheses in a computerized control apparatus (Hint-ELs, Griesheim, Germany) using a partially sintered Y-TZP block (Lava ${ }^{\mathrm{TM}}$ Plus; 3M ESPE, Seefeld, Germany) and additionally fired in the firing furnace (InFire ${ }^{\circledR}$ HTC speed; Sirona $\mathrm{GmbH}$, Bensheim, Germany) at a temperature of $1,450{ }^{\circ} \mathrm{C}$ and held for $120 \mathrm{~min}$ as per the manufacturer's recommendation. The digitally created files of prostheses from CS-3500 were transmitted for milling prostheses in a computerized control apparatus (Ceramill ${ }^{\circledR}$ Motion 2; Amann Girrbach AG) using a partially sintered Y-TZP block (Ceramill ${ }^{\circledR}$ Zolid 71M; Amann Girrbach AG) and then fired in the firing furnace $\left(\right.$ Ceramill ${ }^{\mathbb{B}}$ Therm 3; Amann Girrbach AG) at a temperature of $1,470{ }^{\circ} \mathrm{C}$ and held for $120 \mathrm{~min}$ as per the manufacturer's recommended firing schedule. After completion of the Y-TZP sintering process, the restorations were inserted into the resin casts.

\section{Construction of traditional cast metal prosthesis}

The final impressions of a metal cast were generated through a one step double-mixed technique with a custom tray by mixing a combination of medium and light viscosity polyvinyl siloxane impression (Siligum ${ }^{\circledR}$; DMG, Hamburg, Germany) and then the working model cascaded with the gypsum product type IV improved stone (Vel-Mix ${ }^{\circledR}$; Kerr, Orange, CA, USA). The gypsum hardening liquid (Bredent, Senden, Germany) was lubricated onto the improved stone cast. The colored spacing material (Bredent) was applied to the surface of abutment twice. The one-piece full-arch wax pattern was generated with dental casting wax (Kerr), invested in the high heat dental investment material (Formula- ${ }^{\circledR}$; Whip Mix, Louisville, KY, USA), and then cast with nonprecious casting alloy (4all ${ }^{\circledR}$; Ivoclar Vivadent, Ellwangen, Germany). After completion of the casting process, the prosthesis was devested, finalized, polished, and inserted on the working cast. 


\section{Determination of internal accuracy}

The space replication method was performed to evaluate the internal accuracy of each prosthesis. ${ }^{15}$ The light viscosity polyvinyl siloxane impression material (Silagum; DMG) was carried into each retainer. Then, the prosthesis was placed on the metal model (Figure 2A) and immediately loaded with $50 \mathrm{~N}$ force through the axial direction of the prosthesis for $10 \mathrm{~min}$ to achieve complete polymerization of silicone (Figure 2B). ${ }^{26}$ Then, the prosthesis was detached from the metal arch, leaving a layer of silicone replicating material sticking on the metal dies. The medium viscosity polyvinyl siloxane material was induced to catch the thin film of silicone replica. Suddenly, the medium viscosity polyvinyl siloxane material was imported into the internal surface of the silicone replica for sustaining space replication media as a sandwiching technique. The space replication material was sectioned with the thin surgical blades through the middle portion in the right-left (RL) and anteroposterior (AP) directions for measuring the internal gap of the prosthesis (Figure 3A). The internal accuracies were measured at different positions including the gingival position $\left(\mathrm{P}_{\mathrm{G}}\right)$, gingivo-axial position $\left(\mathrm{P}_{\mathrm{GA}}\right)$, axial position $\left(\mathrm{P}_{\mathrm{A}}\right)$, axio-occlusal position $\left(\mathrm{P}_{\mathrm{AO}}\right)$, occlusal position $\left(\mathrm{P}_{\mathrm{O}}\right)$, and occluso-central position $\left(\mathrm{P}_{\mathrm{OC}}\right)$ using a stereomeasurescope furnished with a video measurement appliance (Nikon Measurescope-20, Nikon D-800, and Nikon SC-102; Nikon, Melville, NY, USA) at $5 \times$ magnification (Figure $3 \mathrm{~B}$ ).

\section{Data analysis}

The internal gaps were scrutinized using the SPSS Inc. software version 17 (Chicago, IL, USA). Analysis of variance (ANOVA) was determined for statistically significant difference of internal accuracy of the prostheses fabricated from the different techniques as a function of prosthesis construction procedure, type of abutments, side, and position for the prosthesis. Tukey's post-hoc pairwise comparison was deployed to evaluate for statistic significance among components at $p<0.05$.

\section{Results}

The means and SDs of internal accuracy for one-piece full-arch prostheses constructed from Y-TZP by both
A

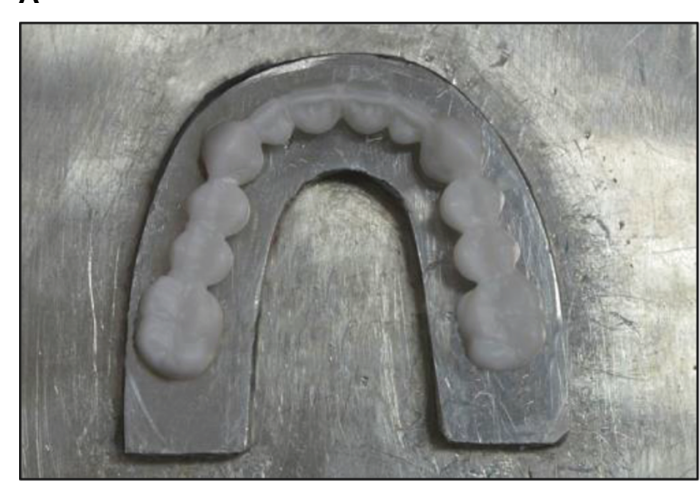

B

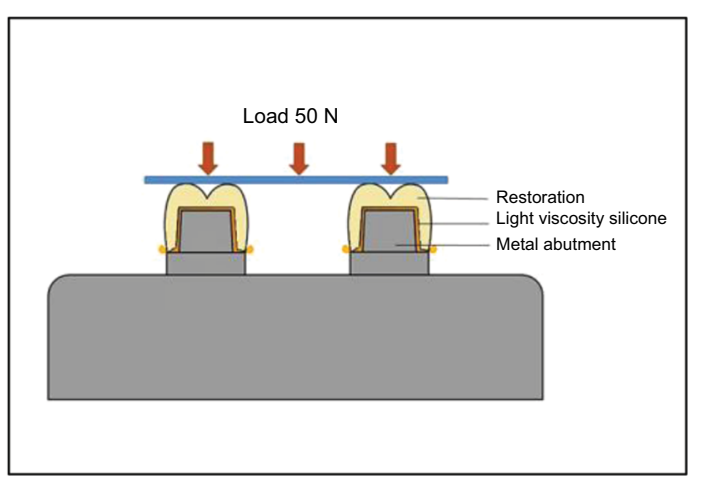

Figure 2 Measurement of internal accuracy of one-piece cross-arch prosthesis on a metal model (A) with an impression replica technique using light viscosity polyvinyl siloxane impression material to replicate the internal space (B).

A

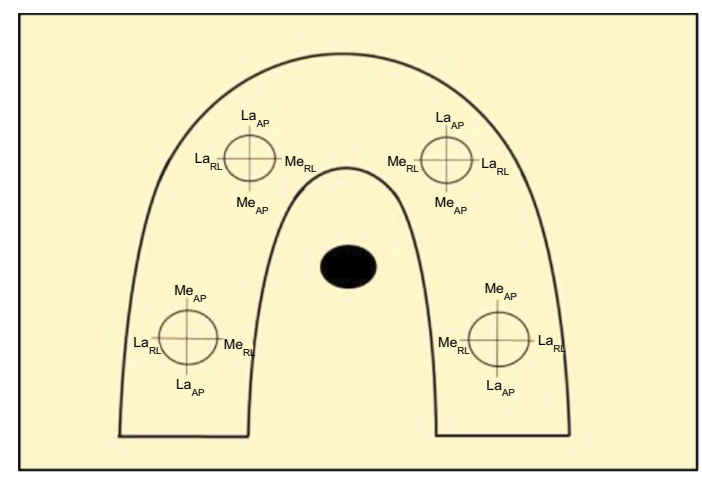

B

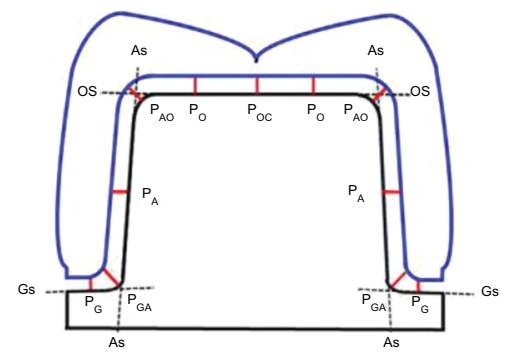

Figure 3 Measurement of internal gap for the lateral (La) and medial (Me) sides of the abutment in the right-left (RL) and anteroposterior (AP) directions (A), at locations of gingival position $\left(\mathrm{P}_{G}\right)$ at mid-gingival surface $(\mathrm{Gs})$, gingivo-axial position $\left(\mathrm{P}_{G A}\right)$ at gingivo-axial surface intersection, axial position $\left(\mathrm{P}_{A}\right)$ at mid-axial surface $($ As), axio-occlusal position $\left(\mathrm{P}_{\mathrm{AO}}\right)$ at axio-occlusal surface intersection, occlusal position $\left(\mathrm{P}_{\mathrm{O}}\right)$ at one-quarter of occlusal surface $\left(\mathrm{O}_{\mathrm{S}}\right)$, and occluso-central position ( $\left.\mathrm{P}_{\mathrm{OC}}\right)$ at mid-occlusal surface (Os) (B). 
digital systems compared to traditional metal alloy casting prostheses were addressed both for the lateral and medial sides of canine and molar abutments at various positions as indicated in Table 1 and Figure 4. The overall means and SDs of internal accuracy for the traditionally fabricated cast metal prosthesis $\left(\mathrm{T}_{\mathrm{CM}}\right)$, the digitally fabricated Y-TZP prosthesis from Trios- $3\left(\mathrm{D}_{\mathrm{Z3S}}\right)$, and the digitally fabricated Y-TZP prosthesis from CS-3500 $\left(\mathrm{D}_{\mathrm{ZCS}}\right)$ were $73.15 \pm 13.46$ $\mu \mathrm{m}, 78.55 \pm 14.30 \mu \mathrm{m}$, and $82.43 \pm 16.32 \mu \mathrm{m}$, respectively (Figure 5). The means and SDs for internal accuracy at the canine and molar abutments were $74.52 \pm 13.96 \mu \mathrm{m}$ and $71.77 \pm 12.80 \mu \mathrm{m}$ for traditional cast metal prosthesis $\left(\mathrm{T}_{\mathrm{CM}}\right), 78.92 \pm 14.32 \mu \mathrm{m}$ and $78.19 \pm 14.27 \mu \mathrm{m}$ for zirconia prosthesis fabricated from Trios- $3\left(\mathrm{D}_{\mathrm{Z} 3 \mathrm{~S}}\right)$, and $83.00 \pm 16.07$ $\mu \mathrm{m}$ and $81.86 \pm 16.57 \mu \mathrm{m}$ for zirconia prosthesis fabricated from CS3500 $\left(\mathrm{D}_{\mathrm{ZCS}}\right)$ as shown in Figure 6. The means and SDs for internal accuracy on the medial and lateral sides of abutment were $73.63 \pm 12.95 \mu \mathrm{m}$ and $72.66 \pm 13.94 \mu \mathrm{m}$ for traditional cast metal prosthesis $\left(\mathrm{T}_{\mathrm{CM}}\right), 79.87 \pm 13.55 \mu \mathrm{m}$ and $77.23 \pm 14.91 \mu \mathrm{m}$ for zirconia prosthesis fabricated from Trios-3 $\left(\mathrm{D}_{\mathrm{Z3S}}\right)$, and $84.45 \pm 15.25 \mu \mathrm{m}$ and $80.40 \pm 17.11 \mu \mathrm{m}$ for zirconia prosthesis fabricated from CS3500 $\left(\mathrm{D}_{\mathrm{ZCS}}\right)$ as demonstrated in Figure 7. The internal discrepancy for onepiece cross-arch prostheses measured at different positions of each abutment for each type of fabrication technique is shown in Figures 8 and 9.

ANOVA disclosed significantly different internal preciseness of one-piece cross-arch prostheses owning to the factor of the technique used for prosthesis construction, type of abutment, side, and position on abutment $(p<0.05)$, except for the interaction between type of abutment and side of prosthesis $(p>0,05)$, as shown in Table 2 . There was no significantly different internal preciseness of restoration as a result of the interaction among three and four factors ( $p>0.05)$, except for the interaction among fabrication technique, position, and abutment type, and the interaction among position, side, and abutment type $(p<0.05)$, as indicated in Table 2.

The internal preciseness of the Y-TZP prosthesis constructed by Trios-3 revealed significantly better accuracy than that constructed from CS-3500 $(p<0.05)$, as indicated in Figures 4 and 5. The Y-TZP prostheses fabricated from both Trios-3 and CS-3500 revealed a significantly higher internal inaccuracy than the traditionally constructed metal casting prosthesis $(p<0.05)$, as indicated in Figures 4 and 5 . There was significant larger internal discrepancy at canine than molar abutment and at the medial than lateral side of abutment for every investigated system $(p<0.05)$ as shown in Figures 6 and 7. The internal discrepancy for the onepiece cross-arch prosthesis measured at different positions for each fabrication technique is shown in Figures 8 and 9. It was indicated that the internal discrepancy of the restoration was significantly larger at the occlusal position $\left(\mathrm{P}_{\mathrm{O}}\right)$ and occluso-central position $\left(\mathrm{P}_{\mathrm{OC}}\right)$ than at the gingivo-axial position $\left(\mathrm{P}_{\mathrm{GA}}\right)$, axio-occlusal position $\left(\mathrm{P}_{\mathrm{AO}}\right)$, axial position $\left(\mathrm{P}_{\mathrm{A}}\right)$, and gingival position $\left(\mathrm{P}_{\mathrm{G}}\right)$, respectively, for all investigated systems ( $p<0.05)$, as indicated in Table 3 and Figures 8 and 9 . However, there was no different statistic significance in the internal discrepancy between the gingivo-axial position $\left(\mathrm{P}_{\mathrm{GA}}\right)$ and axio-occlusal position $\left(\mathrm{P}_{\mathrm{AO}}\right)$ as well as between the occlusal position $\left(\mathrm{P}_{\mathrm{O}}\right)$ and occluso-central position $\left(\mathrm{P}_{\mathrm{OC}}\right)$

Table I Internal accuracy of one-piece cross-arch prostheses fabricated from different techniques including traditional cast metal ( $\left.T_{C M}\right)$, Trios-3 digitally fabricated zirconia $\left(D_{\text {Z3S }}\right)$, and CS-3500 digitally fabricated zirconia $\left(D_{z C S}\right)$, measured at canine and molar abutments, on medial $(\mathrm{Me})$ and lateral $(\mathrm{La})$ sides, at gingival $\left(\mathrm{P}_{\mathrm{G}}\right)$, gingivo-axial $\left(\mathrm{P}_{\mathrm{GA}}\right)$, axial $\left(\mathrm{P}_{\mathrm{A}}\right)$, axio-occlusal $\left(\mathrm{P}_{\mathrm{AO}}\right)$, occlusal $\left(\mathrm{P}_{\mathrm{O}}\right)$, and occluso-central $\left(\mathrm{P}_{\text {oC }}\right)$ positions

\begin{tabular}{|c|c|c|c|c|c|c|c|c|}
\hline \multirow[t]{2}{*}{ Technique } & \multirow[t]{2}{*}{ Abutment } & \multirow[t]{2}{*}{ Side } & \multicolumn{6}{|c|}{ Internal accuracy $(\mu \mathrm{m})$, mean $\pm S D$} \\
\hline & & & $\mathbf{P}_{G}$ & $\mathbf{P}_{\mathrm{GA}}$ & $\mathbf{P}_{\mathbf{A}}$ & $\mathbf{P}_{\mathrm{AO}}$ & $\mathbf{P}_{\mathrm{o}}$ & $\mathbf{P}_{\text {oc }}$ \\
\hline $\mathrm{T}_{\mathrm{CM}}$ & Canine & Me & $55.80 \pm 4.37$ & $77.37 \pm 5.17$ & $61.32 \pm 6.16$ & $76.42 \pm 4.43$ & $88.45 \pm 5.36$ & $89.45 \pm 5.33$ \\
\hline $\mathrm{T}_{\mathrm{CM}}$ & Canine & La & $54.15 \pm 5.73$ & $77.45 \pm 7.82$ & $59.75 \pm 6.31$ & $77.70 \pm 5.06$ & $87.97 \pm 4.60$ & $88.47 \pm 4.83$ \\
\hline $\mathrm{T}_{\mathrm{CM}}$ & Molar & Me & $54.35 \pm 5.61$ & $76.75 \pm 5.62$ & $61.17 \pm 6.47$ & $76.27 \pm 4.43$ & $81.92 \pm 4.50$ & $84.32 \pm 5.01$ \\
\hline $\mathrm{T}_{\mathrm{CM}}$ & Molar & La & $53.20 \pm 5.04$ & $75.85 \pm 6.38$ & $56.20 \pm 5.81$ & $73.67 \pm 5.11$ & $80.70 \pm 5.21$ & $84.25 \pm 5.47$ \\
\hline$D_{\text {z3s }}$ & Canine & $\mathrm{Me}$ & $62.32 \pm 5.63$ & $83.35 \pm 4.87$ & $66.72 \pm 4.76$ & $81.57 \pm 5.20$ & $92.97 \pm 5.17$ & $95.12 \pm 5.66$ \\
\hline$D_{z 35}$ & Canine & La & $56.75 \pm 6.07$ & $78.92 \pm 8.09$ & $63.52 \pm 5.44$ & $77.85 \pm 6.18$ & $92.47 \pm 4.43$ & $94.50 \pm 4.38$ \\
\hline$D_{z 35}$ & Molar & $\mathrm{Me}$ & $58.32 \pm 5.74$ & $83.10 \pm 6.78$ & $68.30 \pm 5.72$ & $81.12 \pm 6.77$ & $92.15 \pm 3.99$ & $93.45 \pm 5.03$ \\
\hline$D_{z 35}$ & Molar & La & $57.77 \pm 5.02$ & $80.37 \pm 5.18$ & $61.07 \pm 6.60$ & $77.52 \pm 5.42$ & $92.12 \pm 4.81$ & $92.87 \pm 4.82$ \\
\hline$D_{z c s}$ & Canine & $\mathrm{Me}$ & $64.07 \pm 4.84$ & $86.67 \pm 5.95$ & $67.92 \pm 5.39$ & $83.35 \pm 5.36$ & $100.1 \pm 4.62$ & $101.5 \pm 4.51$ \\
\hline$D_{z c s}$ & Canine & La & $59.57 \pm 4.64$ & $79.17 \pm 6.60$ & $61.92 \pm 6.71$ & $79.80 \pm 6.22$ & $98.22 \pm 4.05$ & $100.1 \pm 3.76$ \\
\hline $\mathrm{D}_{\mathrm{zcs}}$ & Molar & $\mathrm{Me}$ & $64.37 \pm 6.17$ & $85.82 \pm 5.94$ & $69.15 \pm 5.03$ & $88.10 \pm 7.70$ & $100.4 \pm 3.94$ & $102.2 \pm 3.27$ \\
\hline $\mathrm{D}_{\mathrm{zcs}}$ & Molar & La & $59.42 \pm 6.85$ & $81.35 \pm 6.04$ & $61.02 \pm 6.48$ & $82.45 \pm 6.09$ & $100.1 \pm 3.70$ & $102.0 \pm 3.70$ \\
\hline
\end{tabular}

Note: Trios-3 from 3Shape A/S (Copenhagen, Denmark). CS-3500 from Carestream Health (Rochester, NY, USA). 


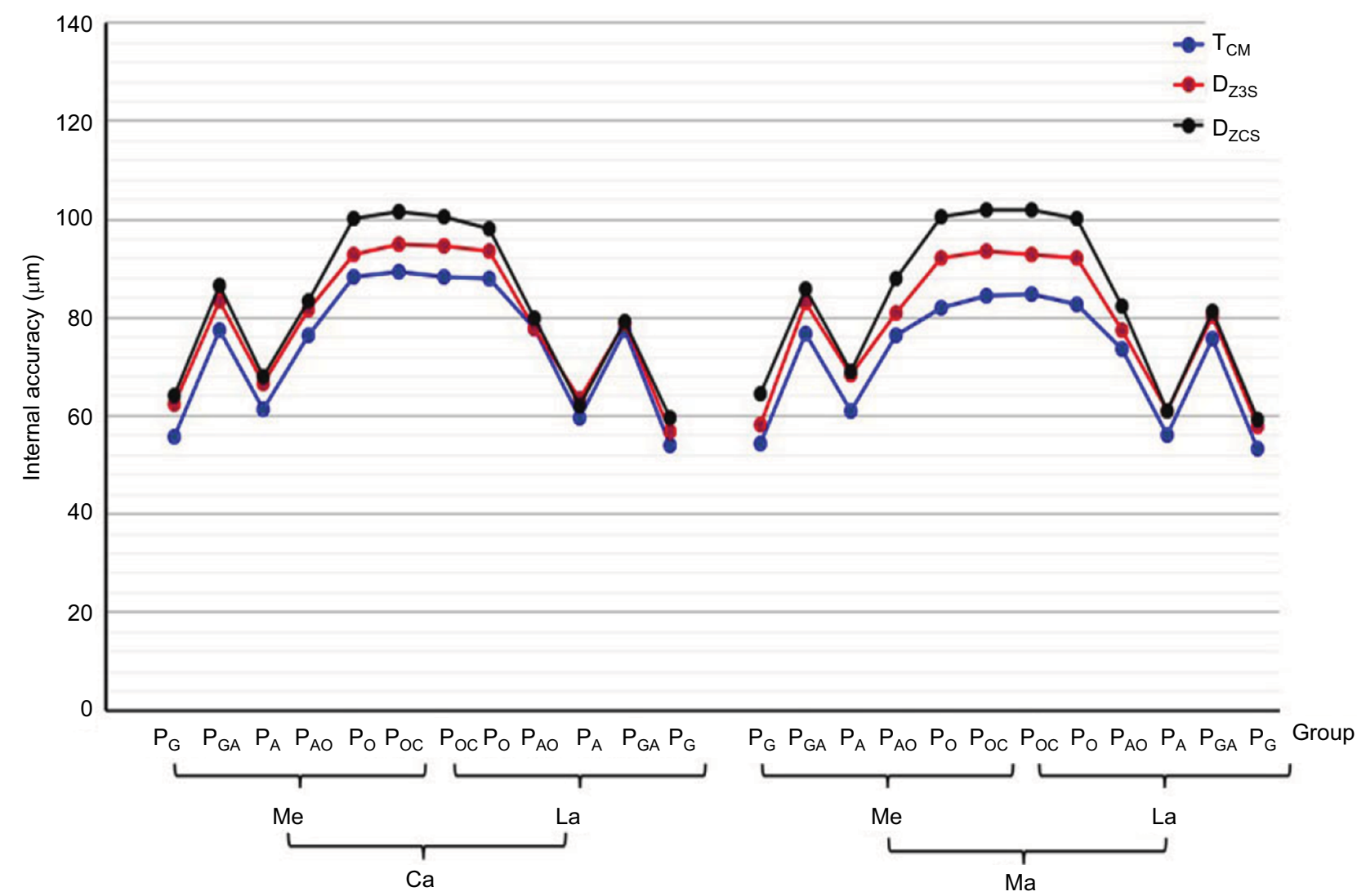

Figure 4 Internal accuracy of one-piece cross-arch prostheses fabricated from traditional cast metal $\left(T_{C M}\right)$, Trios-3 digitally fabricated zirconia $\left(D_{z 35}\right)$, and CS-3500 digitally fabricated zirconia $\left(\mathrm{D}_{\mathrm{zCS}}\right)$, measured at canine $(\mathrm{Ca})$ and molar $(\mathrm{Ma})$ abutments on the medial $(\mathrm{Me})$ and lateral (La) sides at the gingival position $\left(\mathrm{P}_{\mathrm{G}}\right)$, gingivo-axial position $\left(\mathrm{P}_{\mathrm{GA}}\right)$, axial position $\left(\mathrm{P}_{\mathrm{A}}\right)$, axio-occlusal position $\left(\mathrm{P}_{\mathrm{AO}}\right)$, occlusal position $\left(\mathrm{P}_{\mathrm{O}}\right)$, and occluso-central position $\left(\mathrm{P}_{\mathrm{OC}}\right)$.

Note: Trios-3 from 3Shape A/S (Copenhagen, Denmark). CS-3500 from Carestream Health (Rochester, NY, USA).

$(p>0.05)$, as indicated in Table 3. The internal inaccuracy for the Y-TZP prosthesis fabricated from CS-3500 was significantly higher than the Y-TZP restoration constructed from Trios-3 and cast metal restoration for each respective position $(p<0.05)$, as demonstrated in Figures 4 and 9 . The internal discrepancy for one-piece cross-arch prosthesis was significantly higher at the canine than at the molar as well as higher at the medial surface than at the lateral surface in each position for every system that was tested $(p<0.05)$, as demonstrated in Figures 4 and 9.

\section{Discussion}

Despite supreme restrictions in the construction procedure for fixed dental prostheses, imprecision still exists between the prosthesis and the prepared teeth, which initiates tooth abutments to demineralization and periodontitis. ${ }^{4,17}$ The more accurately the restoration adapts to the abutment, the less the gap discloses and the more minor is the luting material dissolved by the saliva. ${ }^{3}$ The accuracy was defined as a seating discrepancy between the prosthesis and the abutment tooth representing the cement space or the internal gap. ${ }^{16}$ Several studies reported that discrepancy of 160-172 $\mu \mathrm{m}$ at the gingival area with a range of $250-300 \mu \mathrm{m}$ at the occlusal area is clinically acceptable discrepancy for full coverage fixed prostheses. ${ }^{4,15,20}$ For this study, the internal gaps of one-piece cross-arch prostheses fabricated from traditional alloy casting, CS-3500 fabricated zirconia, and Trios-3 fabricated zirconia ranged between 51 and $91 \mu \mathrm{m}, 58$ and $104 \mu \mathrm{m}$, and 55 and $97 \mu \mathrm{m}$, respectively, which meant a preciseness of restoration not beyond the acceptable range for clinical conditions. . $^{2,310}$ The precision of one-piece cross-arch prosthesis constructed from each system was of significant difference. Therefore, the null hypothesis was rejected. Although the Y-TZP onepiece full-arch prostheses constructed from both digital approaches had significantly different preciseness compared with the traditional alloy casting prosthesis position, the differences are deemed to be negligible. The concernment in internal imprecision was clinically satisfactory. ${ }^{14,20}$ A previous investigation reported that the internal gaps of three-unit Y-TZP bridges fabricated from different digital systems were 


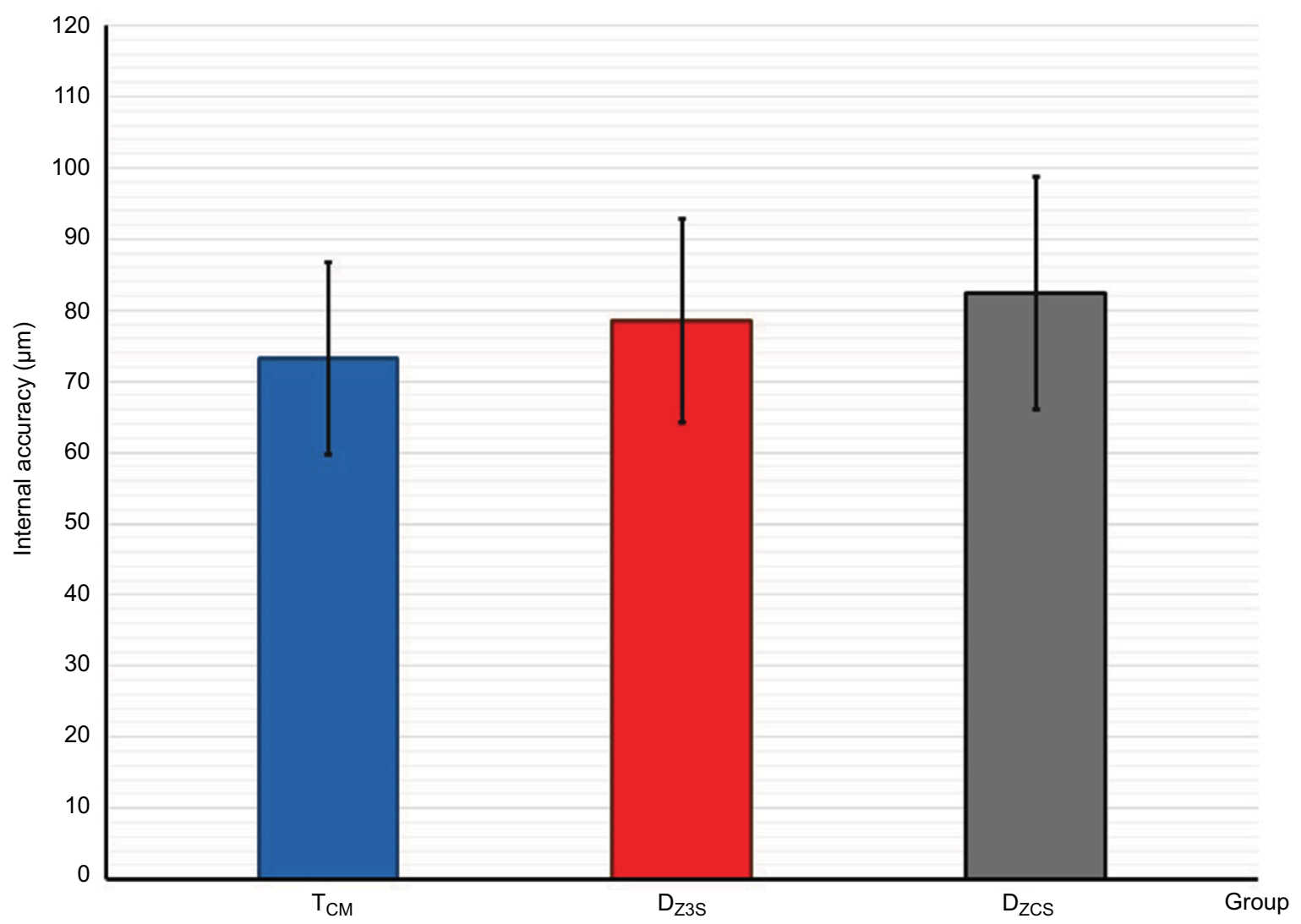

Figure 5 Internal accuracy $(\mu \mathrm{m})$ for one-piece cross-arch prostheses fabricated from traditional cast metal $\left(T_{C M}\right)$, Trios-3 digitally fabricated zirconia $\left(D_{\text {Z3s }}\right)$, and CS-3500 digitally fabricated zirconia $\left(D_{\text {zcs }}\right)$.

Note: Trios-3 from 3Shape A/S (Copenhagen, Denmark). CS-3500 from Carestream Health (Rochester, NY, USA).

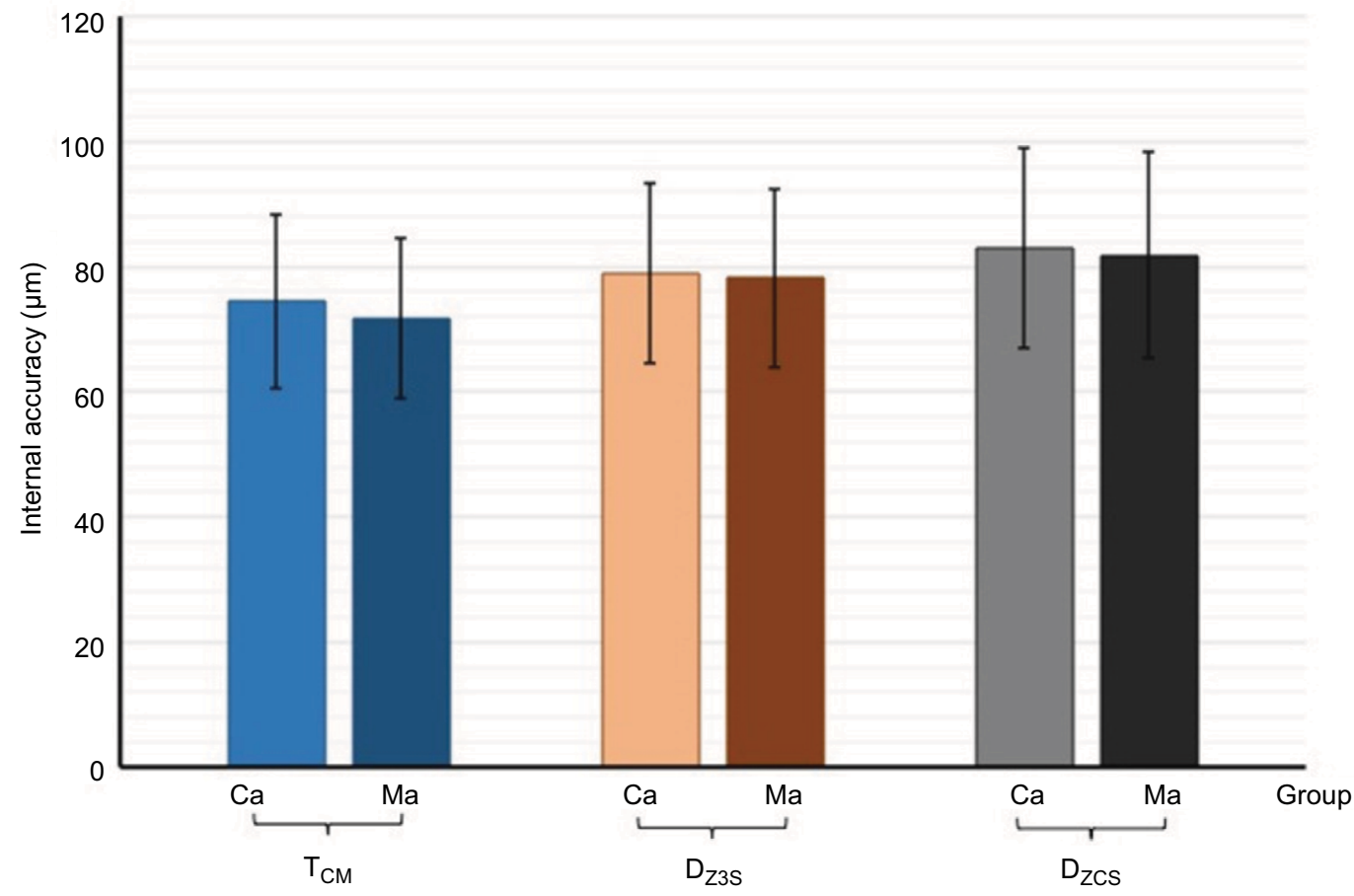

Figure 6 Internal accuracy $(\mu \mathrm{m})$ for one-piece cross-arch prostheses fabricated from traditional cast metal $\left(T_{C M}\right)$, Trios-3 digitally fabricated zirconia $\left(D_{\text {Z3s }}\right)$, and CS-3500 digitally fabricated zirconia $\left(D_{\text {zCS }}\right)$ measured at canine $(\mathrm{Ca})$ and molar $(\mathrm{Ma})$ abutments.

Note: Trios-3 from 3Shape A/S (Copenhagen, Denmark). CS-3500 from Carestream Health (Rochester, NY, USA). 


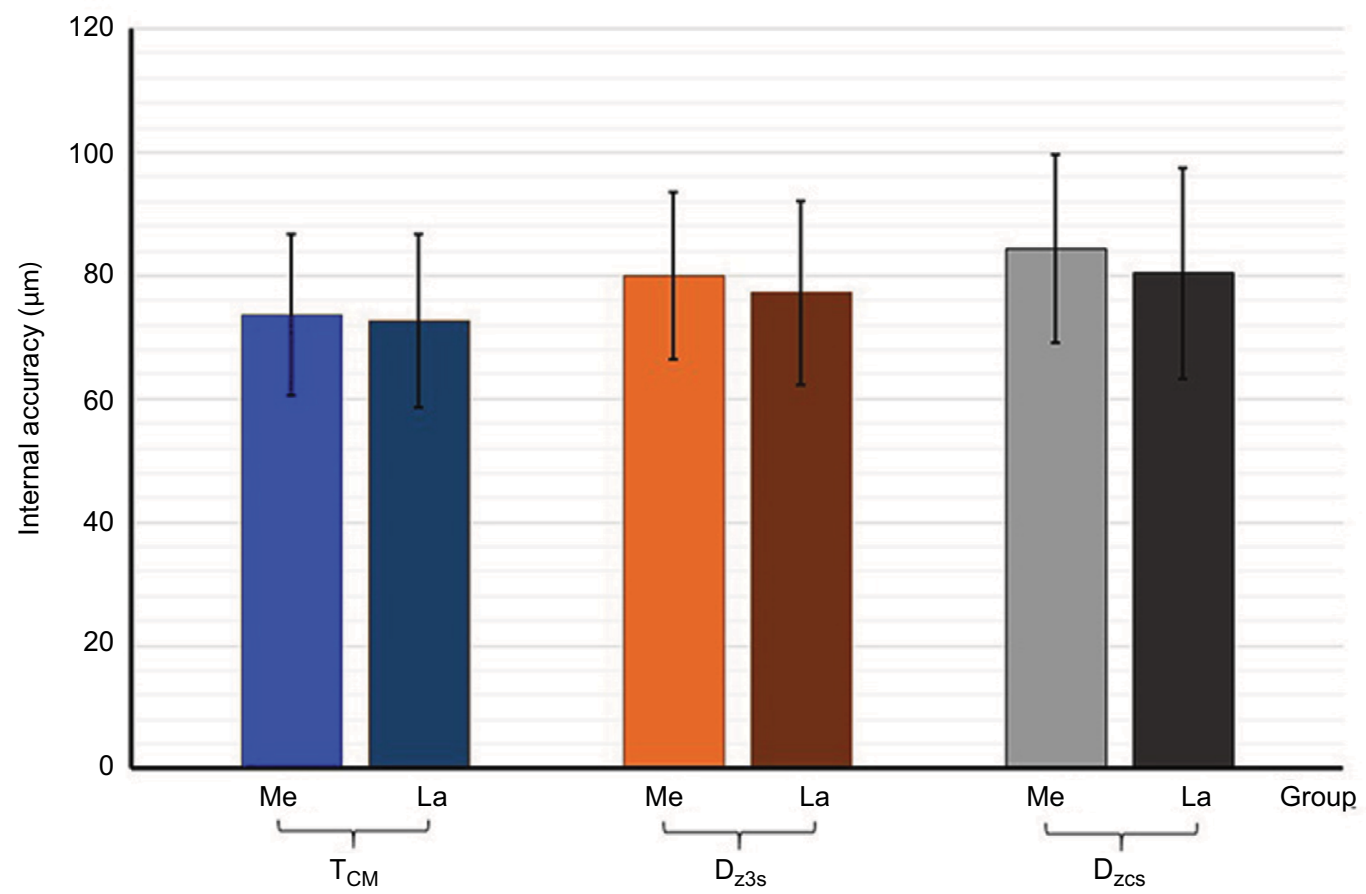

Figure 7 Internal accuracy $(\mu \mathrm{m})$ for one-piece cross-arch prostheses fabricated from traditional cast metal $\left(T_{C M}\right)$, Trios-3 digitally fabricated zirconia $\left(D_{z 3 S}\right)$, and CS-3500 digitally fabricated zirconia $\left(D_{\text {zcS }}\right)$ measured in the medial $(\mathrm{Me})$ and lateral $(\mathrm{La})$ sides.

Note: Trios-3 from 3Shape A/S (Copenhagen, Denmark). CS-3500 from Carestream Health (Rochester, NY, USA).

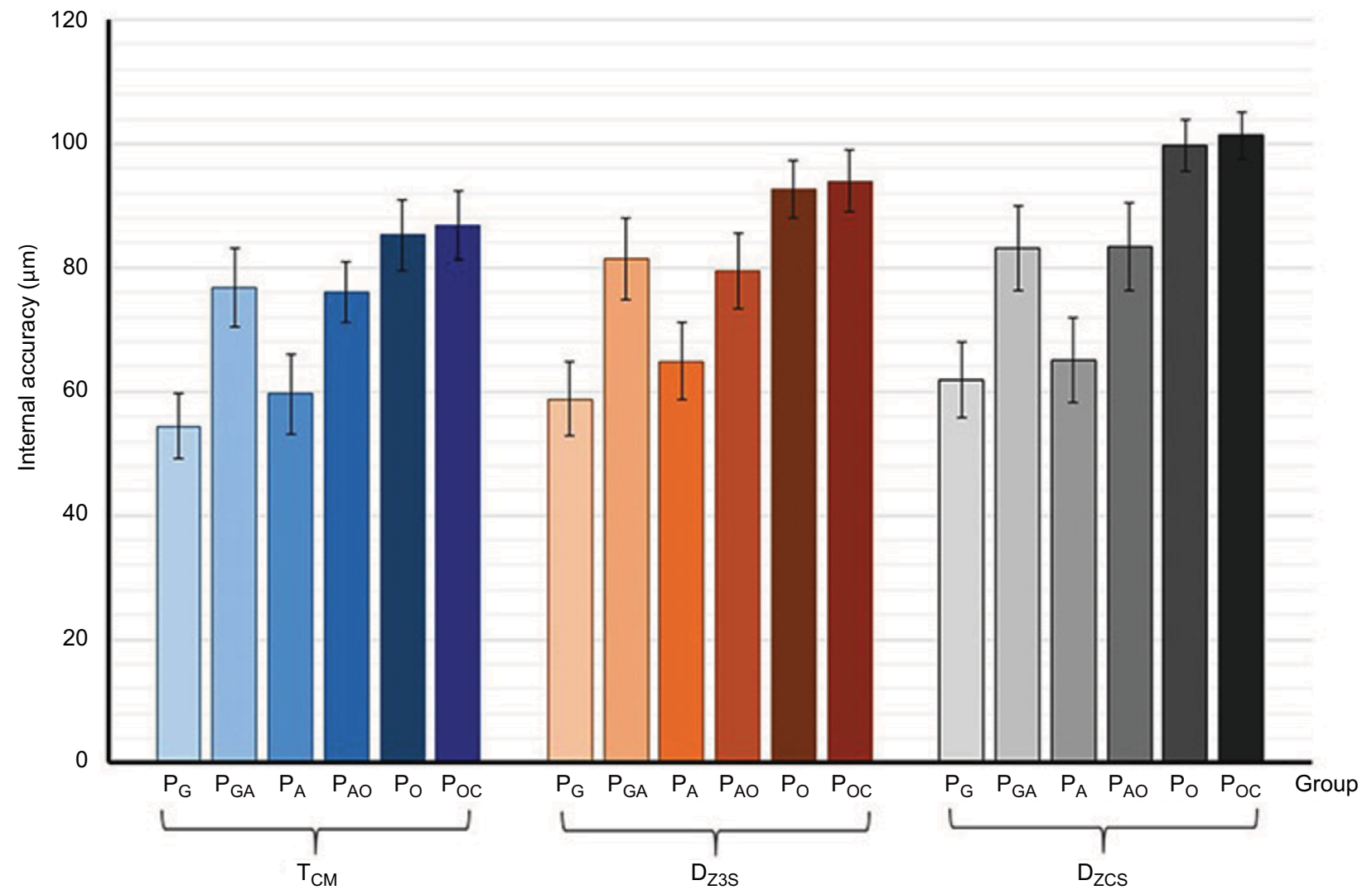

Figure 8 Internal accuracy $(\mu \mathrm{m})$ for one-piece cross-arch prostheses fabricated from traditional cast metal $\left(T_{C M}\right)$, Trios-3 digitally fabricated zirconia $\left(D_{z 3 S}\right)$, and CS-3500 digitally fabricated zirconia $\left(\mathrm{D}_{\mathrm{ZCS}}\right)$, measured at gingival position $\left(\mathrm{P}_{\mathrm{G}}\right)$, gingivo-axial position $\left(\mathrm{P}_{\mathrm{GA}}\right)$, axial position $\left(\mathrm{P}_{\mathrm{A}}\right)$, axio-occlusal position $\left(\mathrm{P}_{\mathrm{AO}}\right)$, occlusal position $\left(\mathrm{P}_{\mathrm{O}}\right)$, and occluso-central position $\left(\mathrm{P}_{\text {OC }}\right)$.

Note: Trios-3 from 3Shape A/S (Copenhagen, Denmark). CS-3500 from Carestream Health (Rochester, NY, USA). 


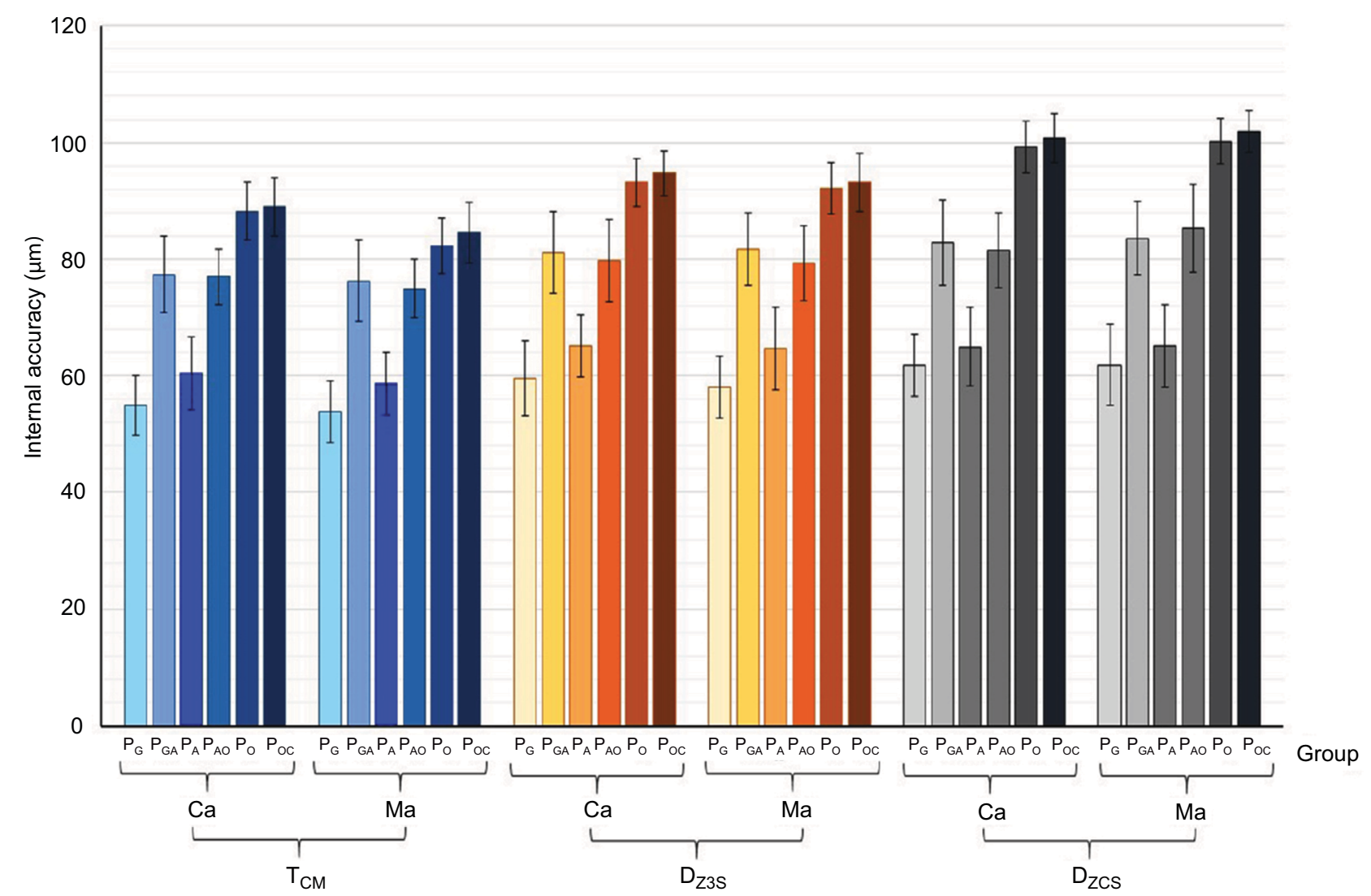

Figure 9 Internal accuracy of one-piece cross-arch prostheses fabricated from traditional cast metal $\left(T_{C M}\right)$, Trios-3 digitally fabricated zirconia ( $\left.\mathrm{D}_{\mathrm{Zzs}}\right)$, and CS-3500 digitally fabricated zirconia $\left(\mathrm{D}_{\mathrm{ZCS}}\right)$ measured at canine $(\mathrm{Ca})$ and molar $(\mathrm{Ma})$ abutments at gingival position $\left(\mathrm{P}_{\mathrm{G}}\right)$, gingivo-axial position $\left(\mathrm{P}_{\mathrm{GA}}\right)$, axial position $\left(\mathrm{P}_{\mathrm{A}}\right)$, axio-occlusal position $\left(\mathrm{P}_{\mathrm{AO}}\right)$, occlusal position $\left(\mathrm{P}_{\mathrm{O}}\right)$, and occluso-central position $\left(\mathrm{P}_{\mathrm{OC}}\right)$.

Note: Trios-3 from 3Shape A/S (Copenhagen, Denmark). CS-3500 from Carestream Health (Rochester, NY, USA).

Table 2 ANOVA of internal accuracy of one-piece cross-arch prostheses fabricated from different techniques and determined from different sides of the abutments at varied positions

\begin{tabular}{|c|c|c|c|c|c|}
\hline Source & SS & df & MS & F-ratio & $p$ \\
\hline Corrected model & $582,297.665$ & 71 & $8,201.376$ & 270.922 & 0.000 \\
\hline Intercept & $17,542,830.235$ & 1 & $17,542,830.235$ & $579,504.604$ & 0.000 \\
\hline Technique & $41,725.169$ & 2 & $20,862.585$ & 689.168 & 0.000 \\
\hline Position & $520,398.736$ & 5 & $104,079.747$ & $3,438.139$ & 0.000 \\
\hline Abutment & 441.800 & 1 & 441.800 & 14.594 & 0.000 \\
\hline Side & $4,692.006$ & 1 & $4,692.006$ & I54.994 & 0.000 \\
\hline Techniquexposition & $7,374.947$ & 10 & 737.495 & 24.362 & 0.000 \\
\hline Technique $\times$ abutment & $\mathrm{I}, 8 \mathrm{I} 8.308$ & 2 & 909.154 & 30.033 & 0.000 \\
\hline Technique $\times$ side & $\mathrm{I}, \mathrm{I} 40.336$ & 2 & 570.168 & 18.835 & 0.000 \\
\hline Position×abutment & 504.521 & 5 & 100.904 & 3.333 & 0.005 \\
\hline Position $\times$ side & $2,088.732$ & 5 & 417.746 & 13.800 & 0.000 \\
\hline Abutment $\times$ side & 1.168 & I & 1.168 & 0.039 & 0.844 \\
\hline Technique $\times$ position $\times$ abutment & 745.733 & 10 & 74.573 & 2.463 & 0.006 \\
\hline Technique $\times$ position $\times$ side & 385.039 & 10 & 38.504 & 1.272 & 0.240 \\
\hline Technique $\times$ abutment $\times$ side & 52.519 & 2 & 26.260 & 0.867 & 0.420 \\
\hline Position $\times$ abutment $\times$ side & 593.719 & 5 & II 8.744 & 3.923 & 0.002 \\
\hline Technique $\times$ position $\times$ abutment $\times$ side & 334.931 & 10 & 33.493 & 1.106 & 0.353 \\
\hline Error & $85,004.100$ & 2,808 & 30.272 & & \\
\hline Total & $18,210,132.000$ & 2,880 & & & \\
\hline Corrected total & 667,30I.765 & 2,879 & & & \\
\hline
\end{tabular}

Abbreviations: ANOVA, analysis of variance; SS, sum of squares; df, degrees of freedom; MS, mean square. 
Table 3 Turkey honest significant difference multiple comparisons for internal accuracy of one-piece cross-arch prostheses fabricated from traditional cast metal $\left(T_{C M}\right)$, Trios-3 fabricated zirconia $\left(D_{Z 3 S}\right)$, and CS-3500 fabricated zirconia $\left(D_{Z C S}\right)$ among different positions (PO) including gingival $\left(P_{G}\right)$, gingivo-axial $\left(P_{G A}\right)$, axial $\left(P_{A}\right)$, axio-occlusal $\left(P_{A O}\right)$, occlusal $\left(P_{O}\right)$, and occluso-central $\left(P_{O C}\right)$ positions

\begin{tabular}{|c|c|c|c|c|c|c|c|c|c|c|c|c|c|c|c|c|c|c|c|}
\hline \multicolumn{2}{|c|}{ Technique } & \multicolumn{6}{|c|}{ Traditional cast metal } & \multicolumn{6}{|c|}{ Trios-3 fabricated zirconia } & \multicolumn{6}{|c|}{ CS3500 fabricated zirconia } \\
\hline & PO & $\mathbf{P}_{G}$ & $\mathbf{P}_{\mathrm{GA}}$ & $\mathbf{P}_{\mathbf{A}}$ & $\mathbf{P}_{\mathrm{AO}}$ & $\mathbf{P}_{\mathrm{o}}$ & $\mathbf{P}_{\text {oc }}$ & $\mathbf{P}_{\mathrm{G}}$ & $\mathbf{P}_{\mathrm{GA}}$ & $\mathbf{P}_{\mathbf{A}}$ & $\mathbf{P}_{\mathrm{AO}}$ & $\mathbf{P}_{\mathrm{o}}$ & $\mathbf{P}_{\text {oc }}$ & $\mathbf{P}_{G}$ & $\mathbf{P}_{\mathrm{GA}}$ & $\mathbf{P}_{\mathbf{A}}$ & $\mathbf{P}_{\mathrm{AO}}$ & $\mathbf{P}_{\mathrm{o}}$ & $\mathbf{P}_{\text {oc }}$ \\
\hline \multirow{6}{*}{$\mathrm{T}_{\mathrm{CM}}$} & $P_{G}$ & $N$ & $\mathrm{~S}$ & $\mathrm{~S}$ & $\mathrm{~S}$ & $\mathrm{~S}$ & $S$ & S & $\mathrm{S}$ & $\mathrm{S}$ & $\mathrm{S}$ & $\mathrm{S}$ & $S$ & $\mathrm{~S}$ & $\mathrm{~S}$ & $\mathrm{~S}$ & $\mathrm{~S}$ & $\mathrm{~S}$ & $\mathrm{~S}$ \\
\hline & $P_{G A}$ & & $\mathrm{~N}$ & $\mathrm{~S}$ & $\mathrm{~N}$ & $S$ & $S$ & $S$ & $S$ & $S$ & $S$ & $S$ & S & $S$ & $S$ & $\mathrm{~S}$ & $S$ & $S$ & $S$ \\
\hline & $\mathrm{P}_{\mathrm{A}}$ & & & $N$ & $\mathrm{~S}$ & $\mathrm{~S}$ & $S$ & $N$ & $S$ & $\mathrm{~S}$ & $\mathrm{~S}$ & $S$ & $S$ & $\mathrm{~N}$ & $S$ & $S$ & $S$ & $S$ & $S$ \\
\hline & $\mathrm{P}_{\mathrm{AO}}$ & & & & $N$ & $S$ & $S$ & $S$ & $S$ & $S$ & $S$ & $S$ & $S$ & $S$ & $S$ & $S$ & $S$ & $S$ & $S$ \\
\hline & $P_{\circ}$ & & & & & $\mathrm{N}$ & $\mathrm{N}$ & $S$ & $\mathrm{~N}$ & $S$ & $\mathrm{~N}$ & $S$ & $S$ & $S$ & $S$ & $S$ & $S$ & $S$ & $S$ \\
\hline & $P_{\text {oc }}$ & & & & & & $\mathrm{N}$ & $S$ & $S$ & $S$ & $S$ & $S$ & $S$ & $S$ & $S$ & $S$ & $S$ & $S$ & $S$ \\
\hline \multirow[t]{6}{*}{$D_{\mathrm{z} 3 \mathrm{~s}}$} & $P_{G}$ & & & & & & & $\mathrm{~N}$ & $\mathrm{~S}$ & $S$ & $S$ & $S$ & $S$ & $\mathrm{~S}$ & $S$ & $S$ & $S$ & $S$ & $S$ \\
\hline & $P_{G A}$ & & & & & & & & $N$ & $S$ & $N$ & $S$ & $S$ & $S$ & $\mathrm{~N}$ & $S$ & $S$ & $S$ & $S$ \\
\hline & $\mathrm{P}_{\mathrm{A}}$ & & & & & & & & & $\mathrm{N}$ & $S$ & $S$ & $S$ & $S$ & $S$ & $S$ & $S$ & $S$ & $S$ \\
\hline & $\mathrm{P}_{\mathrm{AO}}$ & & & & & & & & & & $\mathrm{N}$ & $S$ & $S$ & $S$ & $S$ & $S$ & $S$ & $S$ & $S$ \\
\hline & $P_{\circ}$ & & & & & & & & & & & $\mathrm{N}$ & $N$ & $S$ & $S$ & $S$ & $S$ & $S$ & $S$ \\
\hline & $P_{\text {oc }}$ & & & & & & & & & & & & $\mathrm{N}$ & $S$ & $S$ & $S$ & $S$ & $S$ & $S$ \\
\hline \multirow[t]{6}{*}{$\mathrm{D}_{\mathrm{zcs}}$} & $P_{G}$ & & & & & & & & & & & & & $\mathrm{~N}$ & $S$ & $S$ & $S$ & $S$ & $S$ \\
\hline & $P_{G A}$ & & & & & & & & & & & & & & $\mathrm{~N}$ & $\mathrm{~S}$ & $N$ & $S$ & $S$ \\
\hline & $P_{A}$ & & & & & & & & & & & & & & & $\mathrm{~N}$ & $S$ & $S$ & $S$ \\
\hline & $\mathrm{P}_{\mathrm{AO}}$ & & & & & & & & & & & & & & & & $N$ & $S$ & $S$ \\
\hline & $P_{\circ}$ & & & & & & & & & & & & & & & & & $\mathrm{N}$ & $\mathrm{N}$ \\
\hline & $\mathrm{P}_{\mathrm{OC}}$ & & & & & & & & & & & & & & & & & & $\mathrm{N}$ \\
\hline
\end{tabular}

Note: Trios-3 from 3Shape A/S (Copenhagen, Denmark). CS-3500 from Carestream Health (Rochester, NY, USA).

Abbreviations: $N$, no significant difference $(p>0.05)$; S, significant difference $(p<0.05)$.

significantly larger than the cast metal restorations for every system that was tested, which also supported the results of this study. ${ }^{15}$ Thus, it can be presumed that the different preciseness between the digital systems is associated with the capability of software used for design of the prosthesis in counteraction with the firing contraction of Y-TZP for each digital technique. Also, the CAD-CAM systems require the sintering process of zirconia that might cause the differences in precision.

The accuracy of an indirectly fabricated fixed prosthesis is related to the amount of gap between the abutment and the retainer of the prosthesis. A uniform minimal internal gap is desired for a fixed prosthesis, since a large and inhomogeneous internal gap may create adverse effects in the retention and resistance of the prosthesis. ${ }^{23}$ Most studies do not evaluate the internal fit at different locations as this study did. ${ }^{10,20}$ The thin cement space at the axial and occlusal location was reported to provide favorable influence for the strength of zirconia restorations. ${ }^{21,23}$ An inadequate precision of internal fit was reported to induce risks for ceramic fracture. ${ }^{17,19,24}$ The failure strength of all-ceramic was decreased as the internal gap was increased..$^{21}$ The fracture strength of a ceramic fixed prosthesis possessing cement film thickness between 73 and $122 \mu \mathrm{m}$ at the axial wall was reported to result in the reduction of compressive strength without any significant improvement for the prosthesis seating. ${ }^{21}$ The internal imprecision of a one-piece cross-arch alloy casting fixed dental prosthesis was associated with the three-dimensional accuracy of the conventional lost wax technique during a restoration fabrication process that exactly influenced the prosthesis preciseness. ${ }^{27}$ The one-piece cross-arch Y-TZP prosthesis is produced form the digital approach using an intraoral scanning device for generating digital impression and designing the prosthesis using a three-dimensional software program, and then milling zirconia with a computer-controlled machine. Nevertheless, zirconia restoration ought to behave with the shrinkage of material upon sintering, which is counterbalanced upon designing the restoration in enlarged dimensions using the software. This procedure is contemplated to be an unavoidable flaw associated with any digital system. ${ }^{13}$ The digital impression technique generally generates slightly round borders contingent upon the digital resolution of each scanner, which gives rise to binding contact of the prosthesis at the edge and causes impreciseness. The technique of producing a digital impression also provokes some faulty peaks at the position adjacent to the borders of the scanned substance and leads to aggravate additional impreciseness. ${ }^{28}$ This circumstance has been depicted to be associated with all digital techniques that require a digitizing procedure. The groups of point image gained from the digitizing process are translated into a steady, uneventful area, leaning on the capacity of the 
program to design the prosthesis. This operation usually induces remarkable imprecisions at different positions on each abutment.

The trend to illustrate less internal inaccuracies at the molar compared to the canine probably associated with the geometric configuration of the canine shape, which is tinier in form. A merely slight imprecision related to firing shrinkage may affect the fit of the prosthesis with tiny abutment more strongly than that with bigger abutment. It seems to be quite problematic to achieve a prosthesis to precisely fit with a canine retainer than with a molar retainer, thus the inaccuracies are more prone to happen at canine retainers. Another possible logic may be associated with the quantity of the reconstructive components adjoining each retainer of the prosthesis. Six pontics were connected to each canine retainer, including four pontics mesial jointing both canine retainers from one quadrant to the opposite quadrant and two pontics distal jointing to molar retainers on the identical side. On the other hand, the molar retainers possessed only two pontics secured to the mesial surface for joining with canine retainers in the identical side. The inaccuracy pretends to take effect more at the retainer that has a number of pontics secured owning to the characteristic of prosthesis contraction that appears more toward the mass of material, as indicated by other studies. ${ }^{11,12}$ The occurrence of the internal inaccuracy demonstrating a larger space on the medial surface than the lateral surface of the prosthesis is possibly associated with the nature of prosthesis shrinkage in the cooling process that is illustrated in every direction. The pattern of firing contraction is demonstrated relatively inward to the mid portion of the prosthesis and produces impreciseness at the medial surface higher than at the lateral surface as described by some studies. ${ }^{11,12,20}$

Large internal discrepancies were exhibited at the occlusal and occluso-central region as compared to the other regions. This results in the reduction of the interocclusal distance between the occlusal surface of the prosthesis and the antagonists, and may lead to the limitation of the occlusal anatomy of the prosthesis and can promote higher risks for ceramic fracture. ${ }^{17,19}$ The milling process on zirconia blank also affects the internal accuracy. The narrowest portion of the milling structure is dictated by the smallest dimension of the milling bur used for machining at the internal surface. For the portion of structures smaller than the narrowest milling bur diameter, more zirconia substance may need to be removed than necessary, causing larger internal gaps than expected..$^{28}$ This is the reason for the increasing discrepancies at the axiogingival region and axio-occlusal region that can be attributed to the geometry of the milling. An increase in the cement film thickness leads to a significant decrease in the fracture load of ceramics as well as increasing water absorption by the cement and results in hydrolytic degradation of cements. Thus, a significant reduction in the reliability of ceramics upon large cement space was described..$^{22,23}$

It should be considered that the majority of dentists feel comfortable using conventional cast metal fixed prosthodontic techniques for the fabrication of cross-arch fixed dental prostheses. Since the use of digital dentistry for fabrication, the Y-TZP prostheses are comparatively modern technology and are drastically involved in practicing dentistry nowadays; the information related to the preciseness of prostheses from this investigation found in the systematized situations offers logically profitable scientific evidence for dentists for making decisions in performing one-piece cross-arch prosthetic reconstruction with digitally constructed Y-TZP prostheses in clinical practice. ${ }^{25}$ Therefore, considering the cost-benefit of the digital dentistry, one must consider whether the advantages of the CAD-CAM technique outweigh the familiarity obtained with conventional procedures. ${ }^{18}$ Based on this investigation, both CAD-CAM systems were capable of constructing the one-piece cross-arch Y-TZP prosthesis, with remarkably long span fixed dental prosthesis and convincingly accurate fit. This study also illustrates the feasibility of constructing the sophisticated one-piece cross-arch prostheses using partially sintered Y-TZP blocks. Further investigations are needed to evaluate the impact of digitizing and milling technique on the preciseness of the prosthesis. Furthermore, the ceramic veneering either on cast metal or zirconia may influence the accuracy of prostheses, which need to be further investigated.

\section{Conclusion}

This investigation refused the null hypothesis that the preciseness of prostheses was influenced by different construction techniques. A significantly different internal accuracy of restorations fabricated from both digital approach systems and the traditional metal casting approach was evidenced. Conventionally fabricated cast metal restoration manifested slightly better internal accuracy than digitally fabricated zirconia for each respective location of the retainer. Internal discrepancies of prostheses were larger at the canine than the molar abutment and at the medial than the lateral side of prostheses for both digitally fabricated zirconia and traditionally fabricated cast metal restoration. Nevertheless, the inaccuracies of Y-TZP fixed dental prostheses fabricated from both digital systems were not beyond the ranges of clinical 
acceptability and were commensurate with the conventional metal casting technique. The precise differences of restoration at each location of the retainer were enclosed by the range of clinical prestige for one-piece cross-arch Y-TZP prostheses to be confidently endorsed for advanced dental reconstruction in dental practice.

\section{Clinical significance}

Digital dentistry, based on both Trios-3 and CS-3500 systems, can be contemplated for construction of a one-piece crossarch Y-TZP prosthesis with adequate preciseness. Dentists can be confident of using digital technology for extensive full arch rehabilitation with Y-TZP.

\section{Disclosure}

The authors report no conflicts of interest in this work.

\section{References}

1. Miyazaki T, Nakamura T, Matsumura H, Ban S, Kobayashi T. Current status of zirconia restoration. J Prosthodont Res. 2013;57(4):236-261.

2. Bindl A, Mörmann WH. Marginal and internal fit of all-ceramic CAD/CAM crown-copings on chamfer preparations. J Oral Rehabil. 2005;32(6):441-447.

3. Tinschert J, Natt G, Mautsch W, Spiekermann H, Anusavice KJ. Marginal fit of alumina and zirconia-based fixed partial dentures produced by a CAD/CAM system. Oper Dent. 2001;26(4):367-374.

4. Felton DA, Kanoy BE, Bayne SC, Wirthman GP. Effect of in vivo crown margin discrepancies on periodontal health. J Prosthet Dent. 1991; 65(3):357-364.

5. Denry I, Kelly JR. Emerging ceramic-based materials for dentistry. $J$ Dent Res. 2014;93(12):1235-1242.

6. Kohorst P, Junghanns J, Dittmer MP, Borchers L, Stiesch M. Different $\mathrm{CAD} / \mathrm{CAM}$-processing routes for zirconia restorations: influence on fitting accuracy. Clin Oral Investig. 2011;15(4):527-536.

7. Luthardt RG, Holzhüter M, Sandkuhl O, et al. Reliability and properties of ground Y-TZP-zirconia ceramics. J Dent Res. 2002;81(7):487-491.

8. Hannink RHJ, Kelly PM, Muddly BC. Transformation toughening in zirconia-containing ceramics. J Am Ceram Soc. 2000;83(3):461-487.

9. Beuer F, Schweiger J, Edelhoff D. Digital dentistry: an overview of recent developments for CAD/CAM generated restorations. Br Dent J. 2008;204(9):505-511.

10. Coli P, S. Karlsson S. Precision of a CAD/CAM technique for the production of zirconium dioxide copings. Int J Prosthodont. 2004;17(5):577-580.
11. Kunii J, Hotta Y, Tamaki Y, et al. Effect of sintering on the marginal and internal fit of CAD/CAM-fabricated zirconia frameworks. Dent Mater J. 2007;26(6):820-826.

12. Kokubo Y, Ohkubo C, Tsumita M, Miyashita A, Vult von Steyern P, Fukushima S. Clinical marginal and internal gaps of Procera AllCeram crowns. J Oral Rehabil. 2005;32(7):526-530.

13. Tinschert J, Natt G, Hassenpflug S, Spiekermann H. Status of current $\mathrm{CAD} / \mathrm{CAM}$ technology in dental medicine. Int J Comput Dent. 2004;7(1):25-45.

14. Boitelle P, Mawussi B, Tapie L, Fromentin O. A systematic review of CAD/CAM fit restoration evaluations. J Oral Rehabil. 2014;41(11): 853-874.

15. Reich S, Wichmann M, Nkenke E, Proeschel P. Clinical fit of all-ceramic three-unit fixed partial dentures, generated with three different $\mathrm{CAD} /$ CAM systems. Eur J Oral Sci. 2005;113(2):174-179.

16. Holmes JR, Bayne SC, Holland GA, Sulik WD. Considerations in measurement of marginal fit. J Prosthet Dentist. 1989;62(4):405-408.

17. Sailer I, Fehér A, Filser F, Gauckler LJ, Lüthy H, Hämmerle CH. Fiveyear clinical results of zirconia frameworks for posterior fixed partial dentures. Int J Prosthodont. 2007;20(4):383-388.

18. Raigrodski AJ, Chiche GJ, Potiket N, et al. The efficacy of posterior threeunit zirconium-oxide-based ceramic fixed partial dental prostheses: a prospective clinical pilot study. J Prosthet Dent. 2006;96(4):237-244.

19. Vult von Steyern P, Carlson P, Nilner N. All-ceramic fixed partial dentures designed according to the DC-Zirkon technique. A 2-year clinical study. J Oral Rehabil. 2005;32(3):180-187.

20. McLean JW, von Fraunhofer A. The estimation of cement film thickness by an in vivo technique. Br Dent J. 1971;131(3):107-111.

21. Tuntiprawon M, Wilson PR. The effect of cement thickness on the fracture strength of all-ceramic crowns. Aus Dent J. 1995;40(1):17-21.

22. Silva NR, de Souza GM, Coelho PG, et al. Effect of water storage time and composite cement thickness on fatigue of a glass-ceramic trilayer system. J Biomed Mater Res B Appl Biomater. 2008;84:117-123.

23. Rekow ED, Harsono M, Janal M, Thompson VP, Zhang G. Factorial analysis of variables influencing stress in all-ceramic crowns. Dent Mater. 2006;22(2):125-132.

24. Sailer I, Fehér A, Filser F, et al. Prospective clinical study of zirconia posterior fixed partial dentures: 3-year follow-up. Quintessence Int. 2006;37(9):685-693.

25. Juntavee N, Sirisathit I. Marginal accuracy of computer-aided designand computer-aided manufacturing-fabricated full-arch zirconia restoration. Clin Cosmet Investig Dent. 2018;10:9-17.

26. Proussaefs P. Crowns cemented on crown preparations lacking geometric resistance form. Part II: effect of cement. J Prosthodont. 2004;13(1):36-41.

27. Corso M, Abanomy A, Di Canzio J, Zurakowski D, Morgano SM. The effect of temperature changes on the dimensional stability of polyvinyl siloxane and polyether impression materials. $J$ Prosthet Dent. 1998;79(6):626-631.

28. Pfeiffer J. Dental CAD/CAM technologies: the optical impression (II). Int J Comput Dent. 1999;2(1):65-72.
Clinical, Cosmetic and Investigational Dentistry

Publish your work in this journal

Clinical, Cosmetic and Investigational Dentistry is an international, peer-reviewed, open access, online journal focusing on the latest clinical and experimental research in dentistry with specific emphasis on cosmetic interventions. Innovative developments in dental materials, techniques and devices that improve outcomes and patient satisfac-

\section{Dovepress}

tion and preference will be highlighted. The manuscript management system is completely online and includes a very quick and fair peerreview system, which is all easy to use. Visit http://www.dovepress. com/testimonials.php to read real quotes from published authors. 